\title{
Membrane transport and apoptosis-related proteins in radiation- associated acute myeloid leukemia following the Chornobyl accident
}

\author{
Sergiy V. Klymenko ${ }^{1}$, Iryna N. Ilyenko ${ }^{1}$, Natalya A. Golarnik ${ }^{1}$, Oksana L. Maznichenko', \\ Albert Breier ${ }^{2}$ and Dimitry A. Bazyka ${ }^{1}$ \\ ${ }^{1}$ Research Centre for Radiation Medicine, Academy of Medical Sciences of Ukraine, 53 Melnikova, 04050 Kyiv, Ukraine \\ ${ }^{2}$ Institute of Molecular Physiology and Genetics, Slovak Academy of Sciences, Vlárska 5, 833 34 Bratislava, Slovakia
}

\begin{abstract}
We report on the results of multidrug-resistance transporters (P-glycoprotein, LRP, and MDR1), and apoptosis-related proteins (Fas, Bcl-2, Bax, p53, and Bcl- $\mathrm{X}_{\mathrm{L}}$ ) expression analysis of 56 acute myeloid leukemia (AML) patients by flow cytometry. Of these, there were 21 persons exposed to ionizing radiation due to the Chornobyl accident with radiation-associated and 35 patients with spontaneous AML. Leukemic cells in patients with radiation-associated AML more often overexpressed antiapoptotic protein Bcl-2 $(12 / 21$ vs. $6 / 35, p<0.005)$ and less often demonstrated expression of Fas receptor $(12 / 21$ vs. $30 / 35, p<0.05)$. Moreover, leukemic cells were simultaneously Fas negative and Bcl-2 positive in 4 out of 21 patients exposed to ionizing radiation but none of spontaneous cases had similar phenotype $(p<0.05)$. Patients with radiation-associated AML compared to spontaneous cases more often were P-glycoprotein positive $(12 / 20$ vs. 9/31, $p<0.05)$. P-glycoprotein overexpression significantly correlated with the resistance of the disease to chemotherapy in patients with radiation-associated AML $(p<0.05)$.
\end{abstract}

Key words: Leukemia - Ionizing radiation - Chornobyl accident - Multidrug resistance - P-glycoprotein - Fas - Bcl-2

\section{Introduction}

Numerous epidemiologic studies established a causative link of leukemia with preceding radiation exposure (Doll 1995). Chornobyl accident led to the release of tremendous amount of radioactivity into the environment and caused low-dose external and internal exposure of huge population. The US-Ukrainian case-control retrospective epidemiological study found a significant increase in leukemia with excess relative risk of 3.42 per Gy in a cohort of 110,000 Ukrainian Chornobyl clean-up workers (Romanenko et al. 2008). This data support previous estimates of Ivanov et al. (1997), that up to $30 \%$ of leukemia cases developed in clean-up workers might be attributable to radiation exposure. Evidences on the clinical and morphological specificity of the radiation-associated leukemia are rather controversial. Gluzman (1996) demonstrated the similarity of symptoms and characteristics

Correspondence to: Sergiy V. Klymenko, Research Centre for Radiation Medicine, 53 Melnikova, 04050 Kyiv, Ukraine

E-mail: klymenko_sergiy@yahoo.co.uk of radiation-associated and spontaneous disease. Other groups have described the distinctive features of leukemic cells and myelodysplastic pre-leukemic stage of the radiation-associated acute myeloid leukemia (AML) (Bebeshko et al. 1991, 1999; Klymenko et al. 2005). Moreover, in a previous study we found that AML patients with the history of radiation exposure due to the Chornobyl accident were characterized by unfavorable clinical course and resistance to conventional chemotherapy. They had significantly shorter overall survival (OS), and lower complete remission (CR) rate compared to spontaneous cases (Bebeshko and Klymenko 2004). The clinical behavior suggested that radiation-associated AML differed from the leukemia de novo in terms of tumor cell biology.

During the last two decades, a large number of studies have been designed to investigate the underlying mechanisms involved in the resistance of neoplastic cells to chemotherapy. Multidrug resistance (MDR) may arise from an alteration at any step in the cell-killing pathway. Alterations have been described in membrane transport, drug metabolism, drug targets, cellular repair mechanisms, and in the ability of cells to recognize a toxic insult and engage apoptosis (Sonneveld and List 
2001; Hirose 2002). In the present study using flow cytometric method we examined the expression of drug transporters such as P-glycoprotein (P-gp), lung resistance protein (LRP) and MDR-associated protein (MRP), as well as apoptosis-related proteins such as $\mathrm{Bcl}-2, \mathrm{Bax}, \mathrm{Bcl}-\mathrm{X}_{\mathrm{L}}, \mathrm{p} 53$ and Fas in $\mathrm{AML}$ patients exposed to ionizing radiation due to the Chornobyl accident. The aim of the study was to investigate whether these proteins involved in MDR phenomenon expressed differently in radiation-associated and spontaneous AML cases.

\section{Materials and Methods}

\section{Samples}

Bone marrow $(\mathrm{BM})$ or peripheral blood $(\mathrm{PB})$ samples were collected from 56 unselected adult AML patients, initially diagnosed since 1997. Of these patients, 21 had experienced radiation exposure due to the Chornobyl accident and created the main group, 35 developed spontaneous AML and served as controls. In the group of patients with radiation-associated AML there were 13 clean-up workers and 8 patients either evacuated from the Chornobyl exclusion zone or lived in Ukrainian territories with a high contamination from radioactive fallout. All patients have participated at the study by informed consent. The diagnosis was made using FrenchAmerican-British (FAB) classification. The main clinical characteristics of the patient population are listed in Table 1.

Table 1. Clinical data from acute myeloid leukemia (AML) patients

\begin{tabular}{|c|c|c|c|}
\hline & $\begin{array}{l}\text { Radiation-asso- } \\
\text { ciated AML } \\
(n=21) \\
\end{array}$ & $\begin{array}{c}\text { Spontaneous } \\
\text { AML } \\
(n=35) \\
\end{array}$ & $p$ \\
\hline Age $\left(\right.$ years) ${ }^{\dagger}$ & $54.0(26-74)$ & $43.9(19-80)$ & $<0.05$ \\
\hline Age $\geq 60$ years $^{\dagger}$ & 9 & 8 & 0.2 \\
\hline Gender (male/female) & $17 / 4$ & $24 / 11$ & 0.37 \\
\hline \multicolumn{4}{|l|}{ FAB type } \\
\hline M0 & 1 & 1 & 1.0 \\
\hline M1 & 3 & 3 & 0.66 \\
\hline M2 & 4 & 7 & 1.0 \\
\hline M3 & 2 & 1 & 0.55 \\
\hline M4 & 6 & 14 & 0.56 \\
\hline M5 & 4 & 8 & 1.0 \\
\hline M6 & 1 & 1 & 1.0 \\
\hline WBC $\left(10^{9} / 1\right)^{\dagger}$ & $31.3(0.4-181.4)$ & $23.2(1.0-119.0)$ & 0.41 \\
\hline $\mathrm{WBC} \geq 30 \times 10^{9} / 1^{\dagger}$ & \begin{tabular}{|l|}
8 \\
\end{tabular} & \begin{tabular}{|l|}
8 \\
\end{tabular} & 0.36 \\
\hline AML post MDS & 8 & 5 & 0.09 \\
\hline
\end{tabular}

WBC, white blood cells; MDS, myelodysplastic syndrome; FAB, French-American-British classification; ${ }^{\dagger}$ at time of diagnosis. Median (minimum to maximum) values are indicated in age and WBC. Number of cases is shown in age $\geq 60$ years, gender, FAB type, $\mathrm{WBC} \geq 30 \times 10^{9} / 1$, FAB type and AML post MDS categories.
The term "radiation-associated AML" was used to underline the fact of preceding exposure of patient to ionizing radiation due to the Chornobyl accident. Understanding the conditional character of this term from the etiological point of view, we, however, found it possible to use this term for clean-up workers of the Chornobyl accident, evacuees from and inhabitants of contaminated areas. The similar terminology was introduced earlier for describing witnesses of nuclear explosions and victims of A-bombing (Hromas et al. 2000; Harada et al. 2003). "Radiation-association" as a characteristic pointed to the fact that leukemia developed in a person exposed to ionizing radiation in doses exceeding those from background irradiation and routine diagnostic radiological procedures. According to nonthreshold model of stochastic effects of radiation to human, in the cohort of persons with radiationassociated leukemia there is a part of patients whose leukemia in fact was induced by ionizing radiation. The published data on retrospective dosimetry for clean-up workers and inhabitants of contaminated areas served as a framework to classify a tumor in studied cases as radiation-associated (Likhtarev et al. 1994, 2002; Bouville et al. 2006). The patients with radiation-associated AML did not experience any other mutagen exposure except for irradiation resulted from the Chornobyl accident. The leukemia not associated with any preceding cancerogenous factor was considered as spontaneous.

\section{Methods}

Heparineized whole BM or PB samples were obtained at the time of diagnosis before chemotherapy and processed either fresh or analyzed after storage with $10 \%$ dimethyl sulfoxide in liquid nitrogen. P-gp, LRP, MRP, Bcl- $\mathrm{X}_{\mathrm{L}}, \mathrm{Bax}$, and p53 cell counts were evaluated in an indirect immunofluorescence assay. Briefly, BM or PM $100 \mu \mathrm{l}$ aliquots were incubated for 10 min in $450 \mu$ lof diluted ( $1: 10)$ FACS Lysing solution (Becton Dickinson, San Diego, CA, USA), washed in phosphate-buffered saline containing $0.1 \% \mathrm{Na}$ azide at room temperature, fixed for $30 \mathrm{~min}$ in $70 \%$ ethanol at $4^{\circ} \mathrm{C}$, washed repeatedly and incubated at room temperature for $30 \mathrm{~min}$ with anti-P-gp (MRK16), anti-MRP (MRPm6), anti-LRP (LRP-56) antibodies (Kamiya Biomedical Company, Seattle, WA, USA), and antiBcl-X (BXL03), anti-Bax (2D2), anti-p53 (PAb 240) antibodies (NeoMarkers, Fremont, CA, USA) at final concentration $10 \mu \mathrm{g} / \mu \mathrm{l}$ of each. After washing, cells were incubated with 10 $\mu \mathrm{l}$ of secondary antibody anti-mouse-kappa PE in the dark, washed and analyzed by a flow cytometer FAC Scan (Becton Dickinson). For each sample at least 5000 events were analyzed using Lysis II software. The percentage of positive cells in gated blast region was determined by comparison with histogram of fluorescence of corresponding isotypic control. The case was considered as positive if $20 \%$ and more blast cells expressed the antigen. Fas and $\mathrm{Bcl}-2$ antigens expression was evaluated by the direct immunofluorescence. Briefly, BM or PM $50 \mu \mathrm{l}$ aliquots 
were incubated for $20 \mathrm{~min}$ with $20 \mu \mathrm{l}$ of each anti-Fas PE (3.22) antibody (Kamiya Biomedical Company), and anti-Bcl-2 FITC (124) antibody (Cymbus Biotechnology, Hants, UK) in the dark and incubated for another $20 \mathrm{~min}$ in $450 \mu \mathrm{l}$ of diluted $(1: 10)$ FACS Lysing solution (Becton Dickinson). The stained cells were processed and analyzed as described above.

The fact of clinical treatment resistance was established if CR was not achieved after two courses of chemotherapy or after 42 days after diagnosis.

Analysis of OS times was performed using the KaplanMeier method and the differences were evaluated using the log-rank test. OS was defined as the times from diagnosis to death of any cause, with observations censored for time when patients were last reported to be alive. Nonparametric data were analyzed by Yates' corrected Chi-square test, 2-sided Fisher's exact test was employed as needed. Parametrical data were analyzed by 2 -sided $t$-test. Correlation analysis was performed using Spearman's rank order correlation coefficient $\left(r_{s}\right)$. The following covariates were analyzed: age above 60 , leukocyte count in PB above $30 \times 10^{9} / 1$ at the time of diagnosis, preceding MDS, FAB type and immunologic markers. Differences were considered significant at $p<0.05$. All statistical analyses were done with computer software STATISTICA, version 4.5 (StatSoft, Tulsa, OK, USA).

\section{Results}

The distribution of AML patients in terms of antigen expression positivity ( $20 \%$ and more of cells expressing the antigen)
Table 2. Number of cases with positive antigen expression on bone marrow and peripheral blood blast cells in radiation-associated and spontaneous acute myeloid leukemia (AML)

\begin{tabular}{|l|l|c|c|c|}
\hline Antigen & AML type & $\begin{array}{c}\text { Positive } \\
\text { cases } \\
(n)\end{array}$ & $\begin{array}{c}\text { Negative } \\
\text { cases } \\
(n)\end{array}$ & \\
\hline \multirow{2}{*}{ P-gp } & radiation-associated & 12 & 8 & 0.047 \\
\cline { 2 - 4 } & spontaneous & 9 & 23 & \\
\hline \multirow{2}{*}{ LRP } & radiation-associated & 2 & 18 & \multirow{2}{*}{1.0} \\
\cline { 2 - 4 } & spontaneous & 3 & 29 & \\
\hline \multirow{2}{*}{ MRP } & radiation-associated & 1 & 19 & \multirow{2}{*}{1.0} \\
\cline { 2 - 4 } & spontaneous & 1 & 31 & \\
\hline \multirow{3}{*}{ Bax } & radiation-associated & 1 & 20 & \multirow{2}{*}{0.38} \\
\cline { 2 - 4 } & spontaneous & 0 & 35 & \\
\hline \multirow{2}{*}{ Bcl-2 } & radiation-associated & 3 & 18 & \multirow{2}{*}{1.0} \\
\cline { 2 - 4 } & spontaneous & 4 & 31 & \\
\cline { 2 - 4 } & radiation-associated & 12 & 9 & \multirow{2}{*}{0.005} \\
\hline \multirow{2}{*}{ p53 } & radiation-associated & 1 & 29 & \multirow{2}{*}{1.0} \\
\cline { 2 - 4 } & spontaneous & 1 & 34 & \\
\hline \multirow{2}{*}{ Fas } & radiation-associated & 9 & 21 & 0.026 \\
\cline { 2 - 4 } & spontaneous & 5 & 35 & \\
\hline
\end{tabular}

is presented in Table 2 . The patients with radiation-associated AML more often were P-gp positive, compared to spontaneous cases (Figure 1A,B). Moreover, patients exposed to ionizing radiation had higher average percentage of $\mathrm{P}$-gp positive cells in $\mathrm{BM}$ and $\mathrm{PB}$ (Table 3). Eight cases from the control

Table 3. Mean bone marrow and peripheral blood antigen-expressing blast cells counts (in percentage) in patients with radiation-associated and spontaneous acute myeloid leukemia (AML)

\begin{tabular}{|c|c|c|c|c|}
\hline Antigen & AML type & Median & Range & $95 \% \mathrm{CI}$ \\
\hline \multirow{2}{*}{ P-gp } & radiation-associated $(n=20)$ & $30.61^{\star}$ & $0-87$ & $19.6-41.6$ \\
\hline & spontaneous $(n=32)$ & 15.02 & $0-69$ & $8.8-21.3$ \\
\hline \multirow[t]{2}{*}{ LRP } & radiation-associated $(n=20)$ & 8.51 & $0-97$ & $-1.6-18.7$ \\
\hline & spontaneous $(n=32)$ & 9.13 & $0-99$ & $1.0-17.1$ \\
\hline \multirow[t]{2}{*}{ MRP } & radiation-associated $(n=20)$ & 8.02 & $0-98$ & $-2.2-18.1$ \\
\hline & spontaneous $(n=32)$ & 2.41 & $0-21$ & $0.7-4.2$ \\
\hline \multirow[t]{2}{*}{ Bax } & radiation-associated $(n=21)$ & $4.58^{\dagger}$ & $0-33.9$ & $0.84-8.31$ \\
\hline & spontaneous $(n=35)$ & 1.45 & $0-16.2$ & $0.36-2.54$ \\
\hline \multirow[t]{2}{*}{$\mathrm{Bcl}-\mathrm{X}_{\mathrm{L}}$} & radiation-associated $(n=21)$ & 8.69 & $0-62.9$ & $2.12-15.26$ \\
\hline & spontaneous $(n=35)$ & 8.02 & $0-68.9$ & $2.97-13.06$ \\
\hline \multirow[t]{2}{*}{$\mathrm{Bcl}-2$} & radiation-associated $(n=21)$ & $45.2^{\dagger}$ & $0.01-99.8$ & $26.2-64.1$ \\
\hline & spontaneous $(n=35)$ & 18.8 & $0.01-99.4$ & $7.4-30.1$ \\
\hline \multirow[t]{2}{*}{ p53 } & radiation-associated $(n=21)$ & 3.28 & $0-38.7$ & $0.62-7.17$ \\
\hline & spontaneous $(n=35)$ & 2.75 & $0-55.0$ & $0.54-6.03$ \\
\hline \multirow[t]{2}{*}{ Fas } & radiation-associated $(n=21)$ & $56.2^{\dagger}$ & $0.05-99.0$ & $35.1-77.2$ \\
\hline & spontaneous $(n=35)$ & 80.5 & $0.1-100$ & $70.5-94.5$ \\
\hline
\end{tabular}

CI, confidential interval; ${ }^{*} p<0.01 ;^{\dagger} p<0.05$. 
A

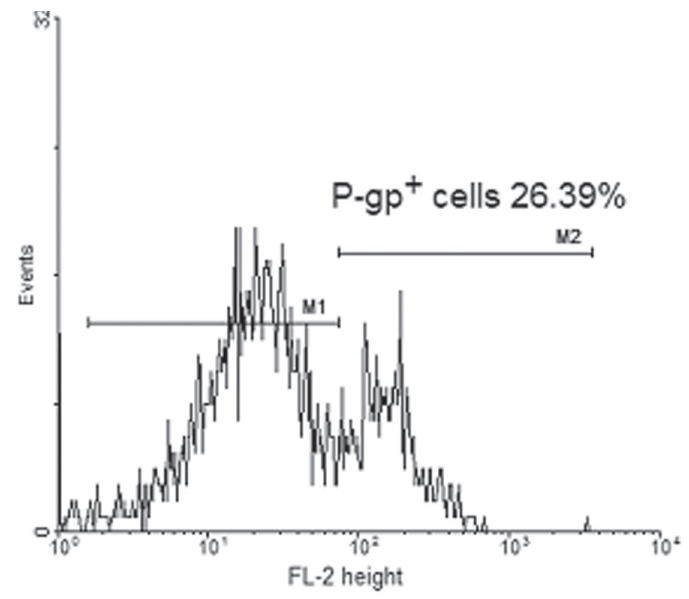

C

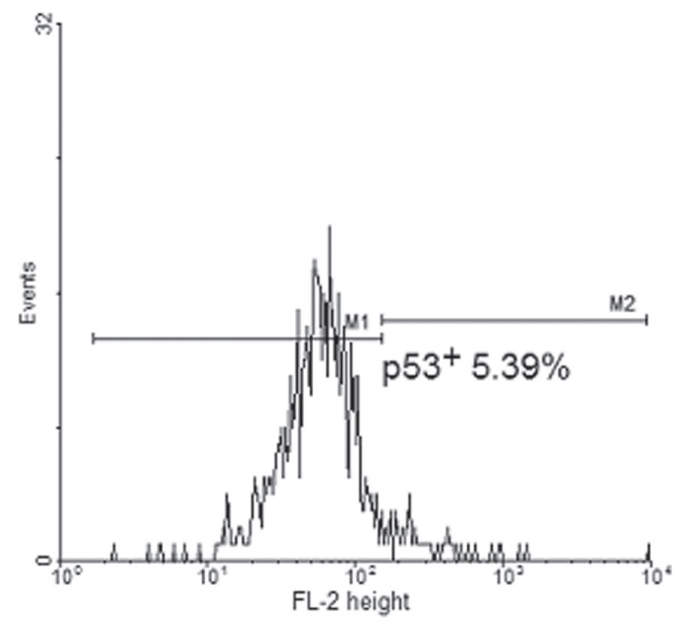

E

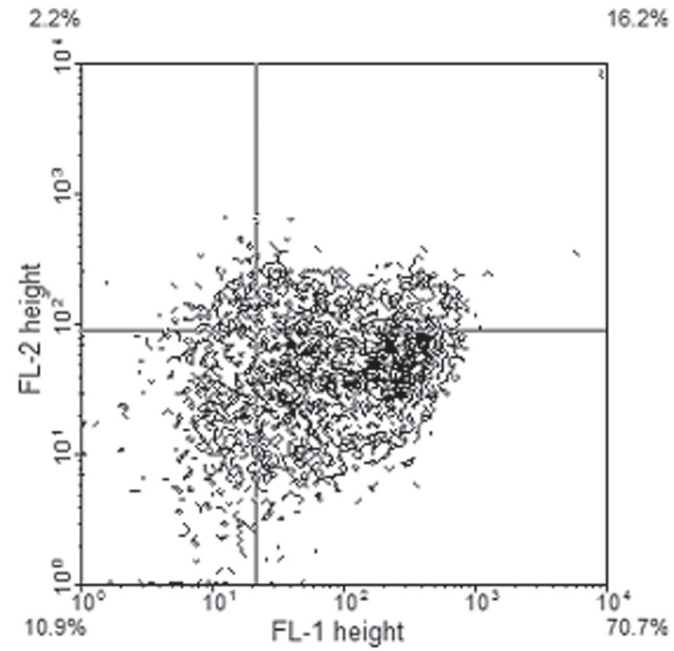

B

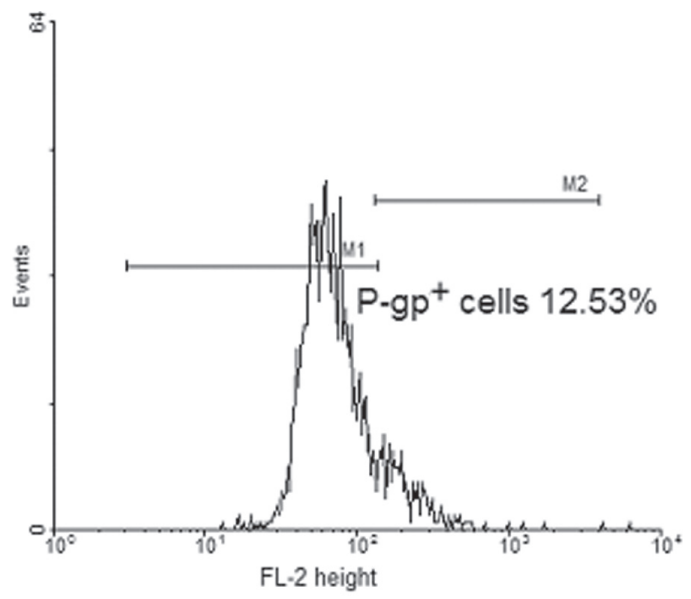

D

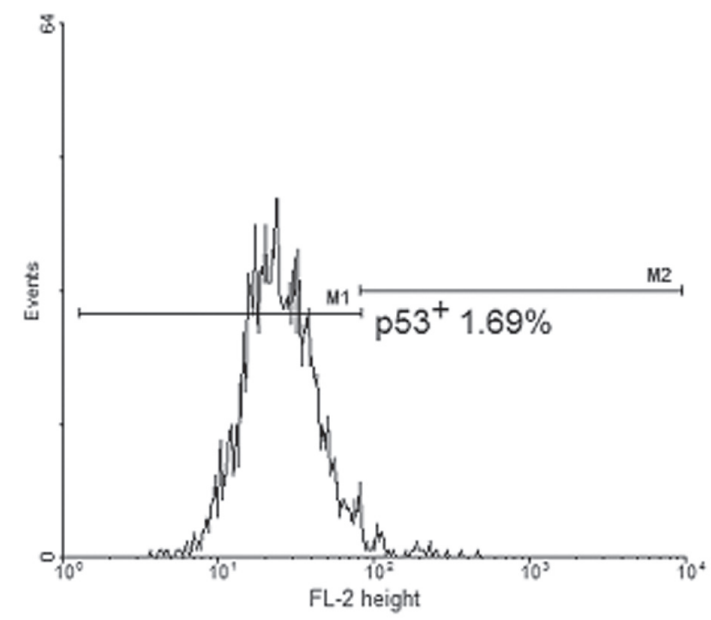

F

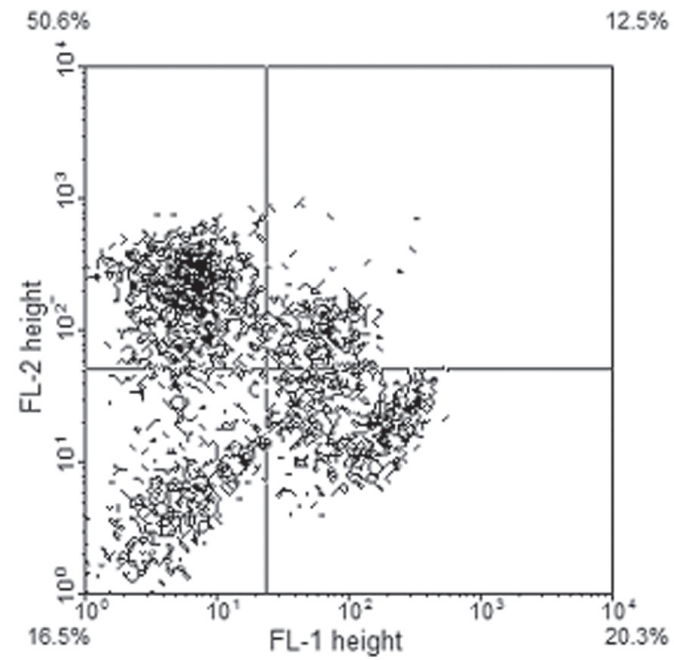

Figure 1. An increase in P-glycoprotein (P-gp) positive cells number (M2-region) in radiation-associated (A) in comparison with spontaneous (B) acute myeloid leukemia (AML) after staining with MRK-16 primary and anti-mouse-kappa PE secondary antibody. An increase in the number of cells reacting with Pab-240 antibody to p53 (M2-region) in radiation-associated (C) in comparison with spontaneous (D) AML after staining with anti-mouse-kappa PE secondary antibody. At dot-plots representing staining with anti-Bcl-2 FITC (FL-1) and anti-Fas PE (FL-2) antibodies a significant increase was shown of Bcl-2 positive cells with moderate Fas expression in radiation-associated AML (E), and substantial Fas expression in spontaneous AML (F). 
group and 7 of radiation-associated AML demonstrated the moderate positivity ranged 20 through $50 \%$ of cells (Figure 1A). In 1 and 5 cases, respectively, the P-gp expression was detected on more than $50 \%$ of cells.

There were no correlations between P-gp overexpression and age above 60 , PB leukocyte counts above $30 \times 10^{9} / 1$ at the time of diagnosis, preceding pre-leukemic myelodysplasia stage, FAB type of the disease. P-gp positivity was associated with CD34 positivity of leukemic cells $\left(r_{s}=0.52 ; p<0.01\right)$. We did not find any difference in OS of P-gp positive and negative patients both in all 52 studied cases and at separate analysis of studied groups. The clinical resistance to chemotherapy was associated with P-gp positivity $\left(r_{s}=0.47, p<\right.$ 0.05). All patients, who reached CR were P-gp negative.

There were no differences between groups in terms of LRP and MRP expression.

The study of AML cases for the expression of apoptosis regulatory proteins (Fas, Bcl-2, Bax, Bcl- $\mathrm{X}_{\mathrm{L}}$ and $\mathrm{p} 53$ ) has demonstrated the increased number of $\mathrm{Bcl}-2$ positive and $\mathrm{Fas}$ negative cases in the group of patients exposed to ionizing radiation compared to patients with spontaneous disease (Table 2) and the difference between groups in terms of mean antigen-expressing blasts counts for Bax, Bcl-2, and Fas (Table 3). The distribution of cases in context of Fas positivity could be described by the pattern "all or nothing" as leukemic cells in overwhelming majority were either Fas negative with borderline fluorescence intensity (Figure 1E) or Fas highly positive (Figure 1F). Difference in p53 fluorescence intensity between radiation-associated and spontaneous cases was not so marked. Partly it could be explained by the peculiarities of the indirect immunofluorescence assay. In some cases there was a significant difference in positive cells percentage (Figure 1C,D). The p53 overexpression frequency was equal.

The assessment of associations between this receptor expression and gender, age of the patient, the presence of prognostic factors attributable to AML, overexpression of other MDR molecules revealed the inverse correlation with age in patients with spontaneous leukemia. The older these patients, more often they were Fas negative $\left(r_{s}=-0.51 ; p<\right.$ $0.005)$. The patients exposed to ionizing radiation did not exhibit the association between age and Fas expression $\left(r_{s}=\right.$ $-0.12 ; p=0.66)$.

The patients with $\mathrm{Bcl}-2$ overexpression were registered statistically frequently in the group of radiation-associated AML compared to the control group. The statement that tumor cells in radiation-associated leukemia compared to spontaneous cases more often were either $\mathrm{Bcl}-2$ positive and/or Fas negative demonstrated at multiparametrical analysis even higher statistical significance $(p<0.001)$. Bcl-2 positivity combined with Fas negativity was found in 4 out of 21 radiation-exposed patients, whereas in none of 35 spontaneous AML cases $(p<0.05)$.
The performed analysis revealed the trends toward the shorter OS in patients with Bcl-2 positive AML compared to $\mathrm{Bcl}-2$ negative leukemia cases, and Fas negative AML compared to Fas positive cases, which did not reach statistical significance.

The correlation analysis displayed the tendency on the border of statistical significance of Bcl-2 positivity being associated with hyperleukocytosis in $\mathrm{PB}$ with white blood cells count higher than $30 \times 10^{9} / 1$ at the time of diagnosis $\left(r_{s}=0.26, p=0.05\right)$. The patients with AML post MDS more often were $\mathrm{Bcl}-2$ positive $\left(r_{s}=0.3, p<0.05\right)$ compared to those without pre-leukemic myelodysplasia stage.

In our study, the indicia of $\mathrm{Bcl}-\mathrm{X}_{\mathrm{L}}$ in $\mathrm{AML}$ patients exposed to ionizing radiation resembled those without radiation history. The correlation analysis revealed the association of Bcl- $\mathrm{X}_{\mathrm{L}}$ positivity with $\mathrm{P}$-gp positivity in the cohort of all AML patients $\left(r_{s}=0.38, p<0.005\right)$. By the separate analysis, the statistical significance of this association retained only in the control group $\left(r_{s}=0.41, p<0.05\right)$, becoming less distinct in the main group $\left(r_{s}=0.35, p=0.1\right)$.

The patients with radiation-associated AML had greater median percentage of tumor cells expressed Bax compared to spontaneous cases. However, there was only one AML case with Bax overexpression registered in inhabitant of contaminated areas, and the difference in overexpression frequency between main and control group was not found.

\section{Discussion}

This report describes the analyses of Chornobyl AML samples using flow cytometric assays to measure membrane transport proteins and apoptosis-related proteins expression in leukemic cells. The results of this study are evidence of the difference between the radiation-associated and spontaneous AML on the expression of some MDR determinants. Patients exposed to ionizing radiation due to the Chornobyl accident more often were P-gp positive. P-gp overexpression is associated with the resistant disease in patients with radiation-associated AML but seems not to be specific for radiation-induced leukemia. There was no difference found in OS of P-gp positive and negative patients both in all 52 cases and at separate analysis of studied groups. These data do not conflict with the results published earlier (Ross 2000; Mahadevan and List 2004). Their authors support the assumption that P-gp expression is a valuable clinical prognostic marker for probability of CR but might not predetermine the shorter OS of AML patients.

The other transport proteins like LRP, MRP seem not to contribute significantly to the MDR phenomenon in radiation-associated AML.

The important reason of multidrug resistance in radiation-associated AML might be the alteration of the apoptotic 
process. The leukemic cells in AML patients exposed to ionizing radiation statistically more often expressed antiapoptotic oncoprotein $\mathrm{Bcl}-2$ and rarely proapoptotic receptor Fas. The difference of tumor cells in radiation-associated compared to spontaneous leukemia in presenting as either $\mathrm{Bcl}-2$ positive and/or Fas negative reached even higher significance. Moreover, radiation-associated nature of the disease frequently was associated with asynchronism of Bcl-2 and Fas expression. Bcl-2 positivity combined with Fas negativity was found in 4 out of 21 exposed patients, whereas in none of 35 spontaneous AML cases $(p<0.05)$. The expression of other apoptosis molecules like $\mathrm{p} 53, \mathrm{Bcl}-\mathrm{X}_{\mathrm{L}}$, and Bax did not differ in patients with radiation-associated and spontaneous AML.

We found that the older the patients with spontaneous leukemia, more often they were Fas negative. In contrast, the AML patients exposed to ionizing radiation did not exhibit the association between age and Fas status. Some authors (Appelbaum et al. 1996; Gluzman 1996) suggested that radiation-associated AML was similar to leukemia developed in patients older than 60 , which was characterized by expression of MDR determinants more often compared to younger patients. Thus, the disappearance of Fas expression dependence from age in the main group might be attributable to the presence of some young patients whose leukemia was induced by ionizing radiation and behaved like leukemia in elderly.

We revealed the tendency of Bcl-2 positivity being associated with hyperleukocytosis in $\mathrm{PB}$ with white blood cells count higher than $30 \times 10^{9} / 1$ at the time of diagnosis. Antiapoptotic properties of $\mathrm{Bcl}-2$ indeed may predetermine the excessive accumulation of leukemic cells by prolonging their terms of life. In fact, the overexpression of antiapoptotic regulators by itself is the indicator of unfavorable prognosis, whereas, the $\mathrm{PB}$ hyperleukocytosis is the indirect evidence of biological peculiarity of leukemia. Moreover, the patients with AML post MDS more often were Bcl-2 positive compared to those without myelodysplastic prephase. Myelodysplasia is considered as one of the main features of the secondary, mutagen-induced leukemia (Appelbaum et al. 1996). Radiation could initiate leukemogenesis and caused more frequent myelodysplastic prephase in AML in patients exposed to ionizing radiation due to the Chornobyl accident. The leukemic cells might become $\mathrm{Bcl}-2$ positive on the stages of tumor evolution evoking transformation of MDS to AML due to the disturbance of Bcl-2-mediated apoptosis (Parker et al. 2000; Invernizzi et al. 2001).

Our findings coincided with the results of other authors demonstrated the frequent coexpression of Bcl- $\mathrm{X}_{\mathrm{L}}$ and $\mathrm{P}-\mathrm{gp}$ in leukemic cells (Irvine et al. 2002; Suárez et al. 2005). The increased activity of transport protein and antiapoptotic changes may cause the resistance of tumor cell to cytotoxic drugs in supplemented manner, thus limiting the potential of their isolated modulation. The universal treatment modali- ties are urgent to overcome the alternative MDR mechanisms in radiation-associated AML.

The limited number of patients in our study did not allow answering the question whether the distinctive features of apoptotic proteins expression converted to the worsening of radiation-associated AML treatment results. However, several lines of evidence indicate that apoptosis plays role in responses of AML patients to chemotherapy. Tumors that demonstrate little or no apoptosis are assumed to be relatively resistant to therapeutic intervention. The interaction of Fas and its ligand plays the key role in the programmed cell death initiated by chemotherapy insult in the treatment of acute leukemia (Debatin and Krammer 1995). The correlation between Fas expression, its function and AML treatment result suggested the involving of Fas-dependant pathway in chemotherapy-induced apoptosis (Wuchter et al. 1999). The apoptosis is the consequence of accumulation of a number of signals where Fas-dependant signaling is only one among others pathways involved. The link of Bcl-2 function with multidrug resistance in AML was studied earlier by Banker et al. (1997). The recent clinical studies demonstrated that overexpression of $\mathrm{Bcl}-2$ was predictive for response to induction therapy and predetermined the unfavorable clinical prognosis in patients with AML (Kasimir-Bauer et al. 2002; Tóthová et al. 2002).

Though, the likely reasons of MDR formation in AML patients exposed to ionizing radiation due to the Chornobyl accident included $\mathrm{P}$-gp and $\mathrm{Bcl}-2$ overexpression, and rare Fas receptor expression. However, the further analysis is needed for understanding of the events regulating the balance of cell proliferation and death, and leading to the leukemic transformation. Such knowledge would help to determine the therapeutic targets and strategies, and characterize the useful diagnostic markers and prognostic indicators in radiation-associated leukemia. The MDR studies described here lay the groundwork for further studies aimed to determine whether intrinsic or radiation acquired resistance contributes to therapeutic outcome.

Acknowledgement. This study was supported in part by the NATO grant PDD(CP)-(CBP.NUKR.CLG 982646).

\section{References}

Appelbaum F. R., Le Beau M. M., Willman C. L. (1996): White cells. In: Secondary leukemia. (Eds. J. R. McArthur and G. P. Schechter), pp. 33-47, American Societa of Hematology, Orlando, USA

Banker D. E., Groudine M., Norwood T., Appelbaum F. R. (1997): Measurement of spontaneous and therapeutic agent-induced apoptosis with bcl-2 protein expression in acute myeloid leukemia. Blood 89, 243-255

Bebeshko V. G., Klimenko V. I., Chumak A. A., Bazyka D. A., Tal'ko V. V., Minchenko Zh. N., Bruslova E. M., Galkina S. G. 
(1991): Clinico-immunocytological characteristics of leukemia in persons exposed to ionizing radiation effects due to the Chernobyl AES accident. Vestn. Akad. Med. Nauk SSSR. 8, 28-31 (in Russian)

Bebeshko V. G. (1999): The issue of pathogenesis of radiation-induced and dyshemopoietic syndromes. Zhurnal AMNU 5, 525-543 (in Russian)

Bebeshko V. G., Klymenko S. V. (2004): Treatment results of acute myeloid leukemia developed in patients exposed to ionizing radiation due to the Chernobyl accident. Ukr. J. Hematol. Transfusiol. 14, 13-18 (in Russian)

Bouville A., Chumak V., Inskip P., Krychkov V., Luckyanov N. (2006): The Chornobyl accident: estimation of radiation doses received by the Baltic and Ukrainian cleanup workers. Radiat. Res. 166, 158-167

Debatin K. M., Krammer P. H. (1995): Resistance to APO-1 (CD95) induced apoptosis in T-ALL is determined by a BCL-2 independent anti-apoptotic program. Leukemia 9, 815-819

Doll R. S. (1995): Hazards of ionizing radiation: 100 years of observations on man. Br. J. Cancer 72, 1339-1349

Gluzman D. F. (1996): Leukemias and myelodysplastic syndromes after the Chernobyl accident. Exp. Oncol. 18, 120-127

Harada H., Harada Y., Tanaka H., Kimura A., Inaba T. (2003): Implications of somatic mutations in the AML1 gene in radiation-associated and therapy-related myelodysplastic syndrome/acute myeloid leukemia. Blood 101, 673-680

Hirose M. (2002): Biology and modulation of multidrug resistance (MDR) in hematological malignancies. Int. J. Hematol. 76, (Suppl. 2), 206-211

Hromas R., Shopnick R., Jumean H. G., Bowers C., Varella-Garcia M., Richkind K. (2000): A novel syndrome of radiation-associated acute myeloid leukemia involving AML1 gene translocations. Blood 95, 4011-4013

Invernizzi R., Pecci A., Bellotti L., Ascari E. (2001): Expression of p53, bcl-2 and ras oncoproteins and apoptosis levels in acute leukaemias and myelodysplastic syndromes. Leuk. Lymphoma 42, 481-489

Irvine A. E., McMullin M. F., Ong Y. L. (2002): Bcl-2 family members as prognostic indicators in AML. Hematology 7 , 21-31

Ivanov V. K., Tsyb A. F., Gorsky A. I., Maksyutov M. A., Rastopchin E. M., Konogorov A. P., Korelo A. M., Biryukov A. P., Matyash V. A. (1997): Leukaemia and thyroid cancer in emergency workers of the Chernobyl accident: estimation of radiation risks (1986-1995). Radiat. Environ. Biophys. 36, 9-16

Kasimir-Bauer S., Beelen D., Flasshove M., Noppeney R., Seeber S., Scheulen M. E. (2002): Impact of the expression of $\mathrm{P}$ glycoprotein, the multidrug resistance-related protein, bcl-2, mutant p53, and heat shock protein 27 on response to induction therapy and long-term survival in patients with de novo acute myeloid leukemia. Exp. Hematol. 30, $1302-1308$
Klymenko S., Trott K., Atkinson M., Bink K., Bebeshko V., Bazyka D., Dmytrenko I., Abramenko I., Bilous N., Misurin A., Zitzelsberger H., Rosemann M. (2005): AML1 gene rearrangements and mutations in radiationassociated acute myeloid leukemia and myelodysplastic syndromes. J. Radiat. Res. 46, 249-255

Likhtarev I. A., Chumack V. V., Repin V. S. (1994): Retrospective reconstruction of individual and collective external gamma doses of population evacuated after the Chernobyl accident. Health Phys. 66, 643-652

Likhtarev I. A., Kovgan L. N., Jacob P., Anspaugh L. R. (2002): Chernobyl accident: retrospective and prospective estimates of external dose of the population of Ukraine. Health Phys. 82, 290-303

Mahadevan D., List A. F. (2004): Targeting the multidrug resistance-1 transporter in AML: molecular regulation and therapeutic strategies. Blood 104, 1940-1951

Parker J. E., Mufti G. J., Rasool F., Mijovic A., Devereux S., Pagliuca A. (2000): The role of apoptosis, proliferation, and the Bcl-2-related proteins in the myelodysplastic syndromes and acute myeloid leukemia secondary to MDS. Blood 96, 3932-3938

Romanenko A. Ye., Finch S. C., Hatch M., Lubin J. H., Bebeshko V. G., Bazyka D. A., Gudzenko N., Dyagil I. S., Reiss R. F., Bouville A., Chumak V. V., Trotsiuk N. K., Babkina N. G., Belyayev Yu., Masnyk I., Ron E., Howe G. R., Zablotska L. B. (2008): The Ukrainian-American study of leukemia and related disorders among Chornobyl cleanup workers from Ukraine: III. Radiation Risks. Radiat. Res. 170, 711-720

Ross D. D. (2000): Novel mechanisms of drug resistance in leukemia. Leukemia 14, 467-473

Sonneveld P., List A. F. (2001): Chemotherapy resistance in acute myeloid leukaemia. Best Pract. Res. Clin. Haematol. 14, 211-233

Suárez L., Vidriales M. B., Moreno M. J., López A., García-Laraña J., Pérez-López C., Tormo M., Lavilla E., López-Berges M. C., de Santiago M., San Miguel J. F., Orfao A. (2005): Differences in anti-apoptotic and multidrug resistance phenotypes in elderly and young acute myeloid leukemia patients are related to the maturation of blast cells. Haematologica 90, 54-59

Tóthová E., Fricova M., Stecová N., Kafková A., Elbertová A. (2002): High expression of Bcl-2 protein in acute myeloid leukemia cells is associated with poor response to chemotherapy. Neoplasma 49, 141-144

Wuchter C., Karawajew L., Ruppert V., Büchner T., Schoch C., Haferlach T., Ratei R., Dörken B., Ludwig W. D. (1999): Clinical significance of CD95, Bcl-2 and Bax expression and CD95 function in adult de novo acute myeloid leukemia in context of P-glycoprotein function, maturation stage, and cytogenetics. Leukemia 13, 1943-1953

Received: January 28, 2008

Final version accepted: January 9, 2009 